\title{
Comparison of Education-Only versus Group-Based Intervention in Promoting Weight Loss: A Randomised Controlled Trial
}

\author{
Yoshio Nakata ${ }^{a, b}$ Masafumi Okada ${ }^{a, b}$ Koichi Hashimoto ${ }^{a, b}$ Yoshinori Harada ${ }^{a, b}$ \\ Hirohito Sone $^{a}$ Kiyoji Tanaka ${ }^{a}$ \\ ${ }^{a}$ Graduate School of Comprehensive Human Sciences, University of Tsukuba, \\ ${ }^{\mathrm{b}}$ Tsukuba Critical Path Research and Education Integrated Leading Center (CREIL), University of Tsukuba, Japan
}

\section{Keywords}

Behavioral interventions - Diet - Metabolic syndrome . Obesity · Physical activity

\section{Summary}

Aim: To compare the effectiveness of education-only versus group-based intervention in promoting weight loss. Methods: Between April and October 2009, a 6-month randomised controlled trial was conducted at Mito Kyodo General Hospital in Japan (UMIN000001259). The participants were 188 overweight adults (145 women, 43 men) aged 40-65 years. They were randomly assigned to one of three groups: control, moderate or intensive intervention. A single motivational lecture was provided to all three groups, educational materials (textbooks, notebooks, and a pedometer) to the moderate and intensive intervention groups, and group-based support to the intensive intervention group. Amount of weight loss was the primary outcome measure. Secondary outcome measures were components of metabolic syndrome. Results: Mean \pm SD weight loss of participants in the control, moderate and intensive intervention groups was $2.9 \pm 4.1,4.7 \pm 4.0$ and $7.7 \pm 4.1 \mathrm{~kg}$, respectively. Bonferroni post-hoc comparisons revealed all between-group differences to be significant $(p<0.05)$. Waist circumference decreased in the intensive intervention group more than in the other groups, whereas no significant differences were observed in the other secondary outcome measures. Conclusion: Education-only intervention is a cost-effective method to promote weight loss. Adding group-based intervention further promotes weight loss.

\section{KARGER}

Fax +497614520714

Information@Karger.de

www.karger.com (c) 2011 S. Karger GmbH, Freiburg

$1662-4025 / 11 / 0043-0222 \$ 38.00 / 0$

Accessible online at:

www.karger.com/ofa

\section{Introduction}

Prevention and treatment of obesity are still a challenge. A typical weight loss treatment entails multiple face-to-face counselling sessions on a wide range of lifestyle recommendations [1-4]. The core behavioural programme includes detailed and frequent monitoring of diet, exercise, and weight, with specific and quantified goals for energy intake and expenditure. In two well-controlled studies that included a lifestyle intervention arm diabetes could be delayed or prevented with only modest changes in weight, but considerable effort from well-trained staff was needed to achieve these behavioural changes [1-4]. A recent meta-analysis of the effectiveness of dietary counselling for weight loss reported its effectiveness but emphasised the importance of determining the factors that will afford more effective weight loss [5]. In most clinical and public health settings, costs in terms of time and physical effort are limited [3, 4]. With detailed evidence of the relative contributions of individual components in weight loss programmes, cost-effective approaches could be selectively used to promote weight loss.

We focused on providing educational materials (textbooks, notebooks, and a pedometer) and implementing group-based support as effective individual components of a weight loss programme. Providing a pedometer or informative materials has been shown to promote physical activity [6-8]. If education-only intervention is effective to promote weight loss, it could be a cost-effective approach. Implementing groupbased intervention could be a reliable method with apparent effectiveness by comparison with the education-only intervention. In weight loss intervention trials, there is a possibility that characteristics of participants who are willing and moti- 
vated may have influenced the trial results $[3,9,10]$. Therefore, we set a control intervention group that was only given a single motivational lecture on weight loss.

Thus, we planned to implement a 6-month randomised controlled trial with three groups: control, moderate or intensive intervention. The control intervention group was given a single motivational lecture on weight loss, the moderate intervention group was additionally provided educational materials, and the intensive intervention group was additionally provided group-based support during the 6-month trial. We determined the effectiveness of each component in the weight loss programme and clarified their relative contributions in promoting weight loss.

\section{Participants and Methods}

\section{Study Design}

The trial methods have been described in detail elsewhere [11]; the protocol has been registered with the UMIN Clinical Trials Registry (UMIN000001259). This study was a 6-month randomised controlled trial conducted at Mito Kyodo General Hospital in Japan between April and October 2009. Assuming a $2.5 \pm 4.0 \mathrm{~kg}$ intervention-related difference in the amount of weight loss at the end of 6 months between the three groups, a two-sided alpha value of 0.0167 (with Bonferroni adjustment for post-hoc tests), power of $80 \%$, and an average attrition rate of $10 \%$, the required sample size was estimated to be more than 60 participants in each group (180 participants in total). Participants received no financial compensation or gifts. The protocol was approved by the ethical committee of Mito Kyodo General Hospital and by the Industrial Review Board of the University of Tsukuba.

\section{Participants}

Participants were recruited through newspaper advertisements and attended a 2-hour explanatory session. In this session, they were informed about the aim and design of the study, including random assignment and the importance of minimising dropout rate for maintaining the study quality. Their written informed consent was obtained, and the time for their baseline measurements was scheduled.

Within 4 weeks before the beginning of weight loss intervention, participants were assessed for eligibility at the baseline measurement. The eligibility criteria for the participants included age between 40 and 65 years, BMI between 25 and $40 \mathrm{~kg} / \mathrm{m}^{2}$ (BMI is calculated as weight in kilograms divided by the square of height in meters), and the presence of at least one of the following components involved in the diagnosis of metabolic syndrome according to the Japanese criteria [12]: i) waist circumference $\geq 85 \mathrm{~cm}$ in males and $\geq 90 \mathrm{~cm}$ in females, ii) systolic blood pressure $\geq$ $130 \mathrm{~mm} \mathrm{Hg}$, iii) diastolic blood pressure $\geq 85 \mathrm{~mm} \mathrm{Hg}$, iv) triglyceride level $\geq$ $150 \mathrm{mg} / \mathrm{dl}(1.70 \mathrm{mmol} / \mathrm{l}), \mathrm{v})$ high-density lipoprotein (HDL) cholesterol level $<40 \mathrm{mg} / \mathrm{dl}(1.04 \mathrm{mmol} / \mathrm{l})$, or vi) fasting plasma glucose level $\geq 110$ $\mathrm{mg} / \mathrm{dl}(6.11 \mathrm{mmol} / \mathrm{l})$. The criteria for ineligibility included drug treatment for diabetes (to avoid a potential influence on weight change [5]), past history of coronary disease or stroke, or current or planned pregnancy. Participants whose cohabiting family member had participated in this study were also ineligible (to avoid contamination from the ripple effect on weight loss [13]).

\section{Motivational Lecture}

At week 0, all participants attended a 2-hour group-based single motivational lecture (approximately 40-50 participants per subgroup, with four subgroups). They received typical behavioural weight control instructions on diet, exercise, and behavioural changes. Recommendations included a calorie-restricted diet of 1,200 and 1,600 kcal/day for women and men, respectively, and a minimum of $1,000 \mathrm{kcal} / \mathrm{week}$ of increased physical activity. All participants were encouraged to self-monitor their body weight. The same investigator gave the lecture using a standard slide presentation to ensure overall comparability of the different subgroups.

\section{Randomisation}

After the motivational lecture, the participants were randomly assigned to one of the following three groups by using simple randomisation procedures involving computerised random numbers: control, moderate or intensive intervention group. Allocation data were generated by an investigator who had no contact with the participants or the other staff members and was maintained at a central secure location until completion of the motivational lecture.

\section{Interventions}

At week 1, following the announcement of the allocated groups through mail, the participants in the moderate and intensive intervention groups attended a group-based 2-hour session (approximately 20-30 participants per subgroup, with four subgroups) in which they were provided educational materials such as textbooks and notebooks containing information on daily diet and other lifestyle-related topics as well as a pedometer (FB-720; Tanita, Tokyo, Japan). The content of the textbooks and notebooks was based on prior work of the investigators $[14,15]$. The goals of energy intake (1,200 and 1,600 kcal/day for women and men, respectively) and increased energy expenditure $(1,000 \mathrm{kcal} / \mathrm{week})$ were the same in all three groups and remained the same throughout the 6 months. The participants in the moderate and intensive intervention groups were recommended to modify their diet along with the provided educational materials. The dietary programme is based on the Four-Food-Group Point Method [16]. According to this method food is organized into four food groups (FG) based on their nutrient contents: FG 1 (eggs and dairy products), FG 2 (meat, fish, and soybean products), FG 3 (vegetables and fruits), and FG 4 (carbohydrates and oil). To calculate energy intakes and nutrient balances easily, a cluster of 80-kcal foods was translated into one point in the method. For consuming a well-balanced daily diet, each person chose 3-point foods from FGs 1 to 3 (9 points in total) to take in the necessary nutrients. Then, depending on a participant's gender, the rest of the energy (6 and 11 in women and men, respectively) was obtained from FG 4 . They were instructed to record their body weight, content of meals, and step counts on a daily basis in the notebook provided. They were also instructed to calculate their daily energy intake and check nutritional balance themselves using the textbooks provided. The same investigator gave the instructions on how to use the educational materials to ensure overall comparability of the different subgroups.

Furthermore, the participants in the intensive intervention group attended a group-based 2-hour weight loss support programme at weeks $2,4,6,10,14,18$, and 22 (approximately 15-20 participants per subgroup, with four subgroups), during which a trained staff member gave lectures to explain the content of the textbooks and two other staff members reviewed participants' notebooks and advised them on their diet and other lifestyle factors. The same staff member gave each lecture to ensure overall comparability of the different subgroups.

\section{Study Outcomes}

Data were collected at baseline and at months 3 and 6 in the hospital by trained hospital staff members who were masked to treatment assignment.

The primary outcome measure was an amount of weight loss from baseline to 6 months. Weight was measured in light clothes, without shoes, to the nearest $0.05 \mathrm{~kg}$ using a calibrated digital scale (WB-150; Tanita). Height was measured to the nearest $0.1 \mathrm{~cm}$ on a wall-mounted stadiometer at baseline for determination of BMI. The secondary out- 


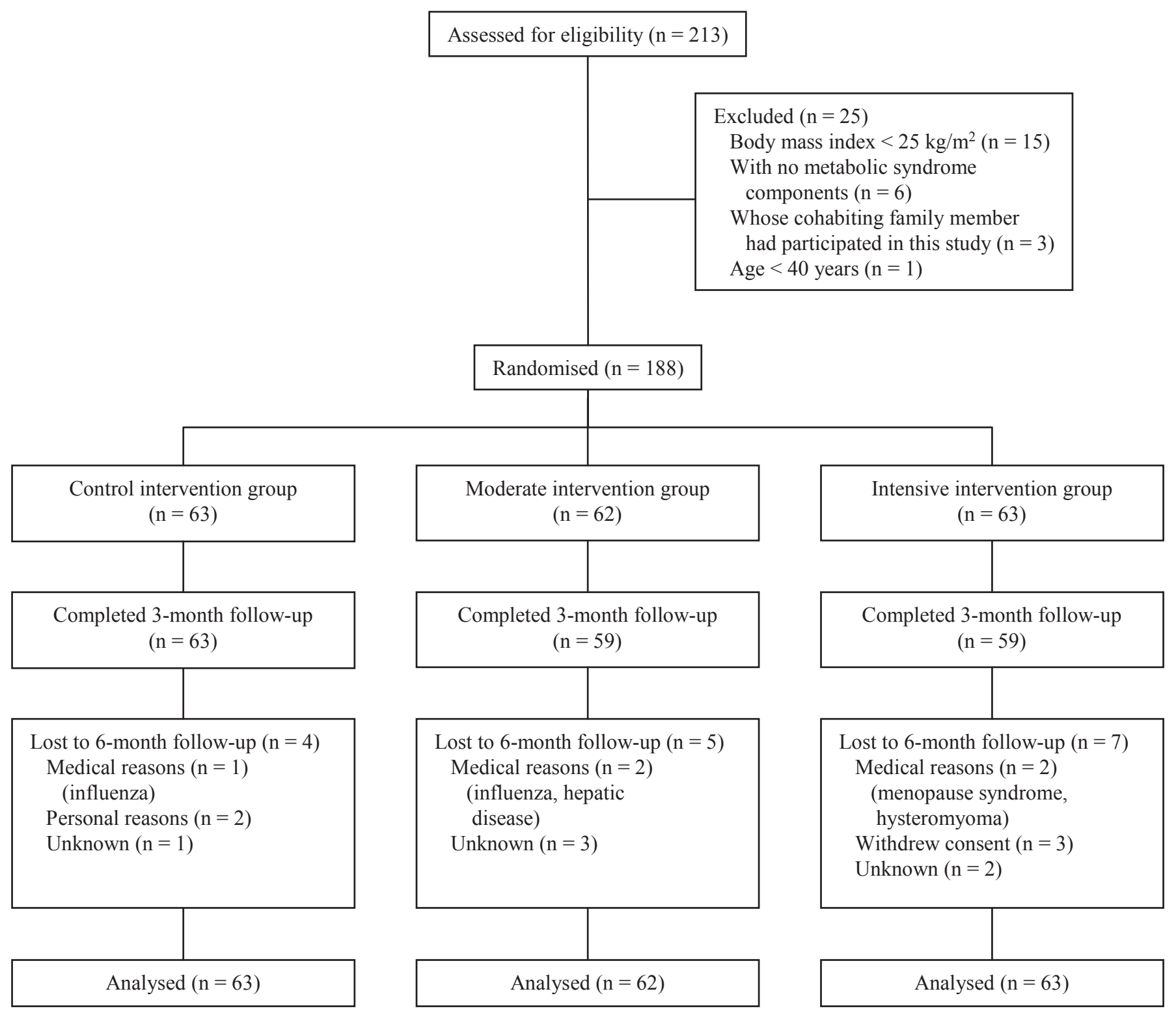

Fig. 1. Flow diagram of participant progress through the phases of the 6-month randomised trial.

come measures were waist circumference, systolic and diastolic blood pressure, levels of triglycerides, HDL cholesterol, and fasting plasma glucose. Waist circumference was measured to the nearest $0.1 \mathrm{~cm}$ at the umbilicus level with the participants in the standing position, using a flexible plastic tape. Blood pressure was measured using a manual sphygmomanometer with the participants in the seated position after a 20-min rest period. Two readings of systolic and diastolic blood pressure were recorded, and the average was used for data analysis. Approximately 10 $\mathrm{ml}$ of blood was drawn from each participant between 10:30 and 11:30 a.m. after fasting for more than $12 \mathrm{~h}$. Fresh samples were used for enzymatic analysis of triglycerides, and fasting plasma glucose was assayed using glucose oxidase. Serum HDL cholesterol was measured using heparin-manganese precipitation. Venous blood was analysed by an independent laboratory (Kotobiken Medical Laboratories, Ibaraki, Japan).

We also measured dietary intake by 3-day food records and physical activity with a three-axis accelerometer (HJA-350IT; Omron Healthcare, Kyoto, Japan) [17]. Participants were asked to record everything that they ate and drank for 3 days - 2 weekdays and 1 weekend day. Foods were measured using standard measuring cups, spoons, and digital scales. To ensure overall comparability, one skilled nutritionist who was masked to treatment assignment analysed all food records. Participants were also asked to wear the accelerometer which additionally includes a step-counting function for 14 consecutive days on their waist throughout the day except when sleeping, when engaged in a water-based activity (e.g., taking a bath or swimming), or when engaged in certain activities such as contact sports for safety reasons. Records obtained when wearing the device for at least $10 \mathrm{~h}$ a day were defined as valid records [18]. If no acceleration signal was obtained over a 10-second time interval for $20 \mathrm{~min}$ or more continuously, it was defined as 'non-wear' [19]. If there are valid records for more than 2 weekdays and 1 weekend day, we estimated daily step counts and total daily minutes of moderate to vigorous ( $\geq 3$ metabolic equivalents) physical activity.

\section{Statistical Analysis}

An intention-to-treat analysis, with missing data replaced by last observation carried forward (data at baseline or month 3), was applied to the 
Table 1. Baseline characteristics of eligible overweight adults by treatment assignment $^{\mathrm{a}}$

\begin{tabular}{|c|c|c|c|c|}
\hline & $\begin{array}{l}\text { Control } \\
\text { intervention } \\
(n=63)\end{array}$ & $\begin{array}{l}\text { Moderate } \\
\text { intervention } \\
(n=62)\end{array}$ & $\begin{array}{l}\text { Intensive } \\
\text { intervention } \\
(\mathrm{n}=63)\end{array}$ & $\begin{array}{l}\text { Total } \\
(\mathrm{n}=188)\end{array}$ \\
\hline Age, years & $51.6(6.2)$ & $51.7(6.8)$ & $50.7(6.7)$ & $51.3(6.6)$ \\
\hline Number of women (\%) & $53(84)$ & $41(66)$ & $51(81)$ & $145(77)$ \\
\hline Number of current smokers (\%) & $4(6)$ & $3(5)$ & $3(5)$ & $10(5)$ \\
\hline Number of lipid-lowering therapies (\%) & $8(13)$ & $9(15)$ & $7(11)$ & $24(13)$ \\
\hline Number of antihypertensive therapies (\%) & $15(24)$ & $18(29)$ & $11(17)$ & $44(23)$ \\
\hline Height, $\mathrm{cm}$ & $157.2(7.6)$ & $160.0(9.0)$ & $159.1(7.2)$ & $158.8(8.0)$ \\
\hline Weight, kg & $71.0(10.1)$ & $74.9(12.1)$ & $73.5(9.9)$ & $73.1(10.8)$ \\
\hline $\mathrm{BMI}, \mathrm{kg} / \mathrm{m}^{2}$ & $28.6(2.8)$ & $29.2(3.8)$ & $29.0(3.0)$ & $28.9(3.2)$ \\
\hline Waist circumference, $\mathrm{cm}$ & $98.7(7.3)$ & $100.7(7.9)$ & $99.2(7.3)$ & $99.5(7.5)$ \\
\hline Systolic blood pressure, $\mathrm{mm} \mathrm{Hg}$ & $131.5(19.5)$ & $131.2(14.5)$ & $131.9(16.4)$ & $131.6(16.8)$ \\
\hline Diastolic blood pressure, $\mathrm{mm} \mathrm{Hg}$ & $78.4(10.6)$ & $80.2(7.4)$ & $79.9(10.2)$ & $79.5(9.5)$ \\
\hline Triglycerides, mmol/1 & $1.67(0.91)$ & $1.80(0.81)$ & $1.45(0.68)$ & $1.64(0.82)$ \\
\hline HDL cholesterol, mmol/1 & $1.49(0.37)$ & $1.39(0.34)$ & $1.49(0.31)$ & $1.46(0.35)$ \\
\hline Fasting plasma glucose, $\mathrm{mmol} / \mathrm{l}$ & $5.35(0.61)$ & $5.50(0.96)$ & $5.25(0.59)$ & $5.37(0.74)$ \\
\hline Dietary intake, kcal/day & $2050(397)$ & $2181(417)$ & $2169(414)$ & $2133(411)$ \\
\hline Step counts, steps/day ${ }^{\dagger}$ & $5677(2565)$ & $6198(2740)$ & $6435(3016)$ & $6100(2782)$ \\
\hline MVPA, $\min /$ day $^{\dagger}$ & $94(34)$ & $86(30)$ & $93(35)$ & $91(33)$ \\
\hline
\end{tabular}

$\mathrm{HDL}=$ High-density lipoprotein; MVPA = moderate to vigorous physical activity

${ }^{a}$ Data are presented as mean (SD) unless otherwise specified.

${ }^{\dagger}$ Eligible data were available for 186 participants $(63,61$, and 62 in the control, moderate, and intensive intervention groups, respectively). measures of body weight and related outcome variables. One-way analysis of variance and Bonferroni's post-hoc test was used to examine statistical significance of between-group differences. The chi-square test was used to compare proportions. Data were analysed using IBM SPSS Statistics 18 (SPSS Inc., Chicago, IL, USA), with the level of statistical significance set at $5 \%$

\section{Results}

Figure 1 shows the flow of participants through the study. We recruited 222 participants between November 2008 and March 2009 and assessed 213 participants for eligibility (9 did not attend). After excluding 25 ineligible participants, 188 adults (145 women and 43 men) were enrolled in the study and were assigned to one of three groups.

Table 1 provides baseline characteristics of the participants. The numbers of those with abdominal obesity, hypertension, lipidaemia and hyperglycaemia were 179 (95\%), 102 (54\%), $59(31 \%)$ and $22(12 \%)$, respectively. The attrition rate was $3.7 \%(7 / 188)$ and $8.5 \%(16 / 188)$ at months 3 and 6 , respectively (fig. 1). The numbers of those lost to follow-up at 6 months were similar in the three groups $(p=0.63)$. The medical reasons for which participants were lost to follow-up included influenza, hepatic disease, menopause syndrome, and hysteromyoma. No clinically significant adverse events occurred that were judged by the investigators to be related to participation in the trial. The attendance rate at the groupbased support in the intensive intervention group ranged from
$57.1 \%(36 / 63$ at week 22$)$ to $96.8 \%$ (61/63 at week 1$)$, and the mean attendance rate was $80.8 \%$.

The pattern of weight change is shown in figure 2 . The mean \pm SD body weights of participants in the control, moderate, and intensive intervention groups declined by $2.4 \pm 2.9$ $\mathrm{kg}, 3.9 \pm 3.1 \mathrm{~kg}$, and $6.0 \pm 3.0 \mathrm{~kg}$ at 3 months, and by $2.9 \pm 4.1$ $\mathrm{kg}, 4.7 \pm 4.0 \mathrm{~kg}$, and $7.7 \pm 4.1 \mathrm{~kg}$ at 6 months, respectively, as determined by intention-to-treat analysis. Bonferroni posthoc comparisons revealed all between-group differences to be significant. Mean weight loss at 6 months in the intensive intervention group was by $4.8 \mathrm{~kg}$ ( $95 \%$ confidence interval (95\% CI) $3.1-6.6 \mathrm{~kg}$; $\mathrm{p}<0.01)$ and $3.0 \mathrm{~kg}(95 \%$ CI $1.3-4.8 \mathrm{~kg}$; $\mathrm{p}<0.01)$ greater than those in the control and moderate intervention groups, respectively. Mean weight loss in the moderate intervention group was also $1.8 \mathrm{~kg}$ (95\% CI $0.0-3.5 \mathrm{~kg}$; $\mathrm{p}=0.04$ ) greater than that in the control group.

The mean percentages of initial body weight lost at 6 months were $4.1 \%$ (95\% CI $2.7-5.5 \%$ ), $6.4 \%$ (95\% CI $5.1-$ $7.7 \%$ ) and $10.5 \%$ (95\% CI 9.2-11.8\%) in the control, moderate and intensive intervention groups, respectively. The numbers of participants who lost $5 \%$ or more of initial body weight were $18(29 \%), 35(56 \%)$, or $56(89 \%)$, and the numbers who lost $10 \%$ or more were $10(16 \%), 17(27 \%)$, or 34 $(54 \%)$ in the control, moderate, or intensive intervention groups.

Table 2 shows changes in the secondary outcome measures, dietary energy intake, and physical activity. The mean decrease in waist circumference in the intensive intervention 
group was by $5.2 \mathrm{~cm}(95 \%$ CI $3.2-7.1 \mathrm{~cm} ; \mathrm{p}<0.01)$ and $3.4 \mathrm{~cm}$ $(95 \%$ CI $1.5-5.4 \mathrm{~cm} ; \mathrm{p}<0.01)$ greater than those in the control and moderate intervention groups, respectively. No significant between-group differences were observed with regard to the other secondary outcome measures. The participants in the intensive intervention group decreased their dietary intake by $412 \mathrm{kcal} /$ day $(95 \%$ CI $241-583 \mathrm{kcal} /$ day; $\mathrm{p}<0.01$ ) and $264 \mathrm{kcal} / \mathrm{day}(95 \% \mathrm{CI} 92-436 \mathrm{kcal} / \mathrm{day} ; \mathrm{p}<0.01)$ more than the participants in the control and moderate intervention groups, respectively. Step counts and moderate to vigorous physical activity increased, while no significant betweengroup differences were observed.

\section{Discussion}

The 6-month randomised controlled trial provides evidence that using educational materials and group-based support are effective components of weight-loss programmes. Educationonly intervention produced an additional weight loss of $1.8 \mathrm{~kg}$ compared with the single motivational lecture. Group-based intervention further increased weight loss by $3.0 \mathrm{~kg}$ compared with the education-only intervention.

In weight loss intervention trials, well-designed randomised controlled trials are needed to avoid potential influences on the trial results by the characteristics of participants who are willing and motivated $[3,9,10]$. In this study, the participants in the control intervention group tried to lose weight only with self-help after a single motivational lecture. Indeed, they had a mean loss of $2.9 \mathrm{~kg}$ after 6 months. These changes may represent the effect of the single lecture and/or the characteristics of highly motivated individuals. In either case, we could clearly show the effectiveness of providing educational materials and group-based support compared with the control intervention.

Providing a pedometer has been shown to promote physical activity and decrease BMI [6, 7]. Providing informative materials seems to also promote physical activity levels among inactive patients [8]. In the present study, education-only intervention as well as group-based intervention could not significantly increase physical activity compared with the control intervention, but could decrease body weight and dietary intake. Therefore, the significant differences in weight loss could be attributed to a greater reduction in dietary intake, and not to an increase in physical activity. This is probably the influence of the behavioural changes stimulated by our emphasising the importance of recording diet and checking nutritional balance themselves for achieving short-term weight loss using the textbook provided to the moderate and intensive intervention groups. Another strategy is needed to promote physical activity in addition to providing a pedometer for participants of the weight loss programme.

A need for effective behavioural interventions requiring less face-to-face contact has been created because of pre- 
Fig. 2. Pattern of change in body weight during 6-month intervention by treatment assignment. Each data point represents the mean value for all randomised participants with missing data replaced by the last observation carried forward. Error bars indicate $95 \%$ confidence intervals. Points and error bars are jittered horizontally to improve visibility.

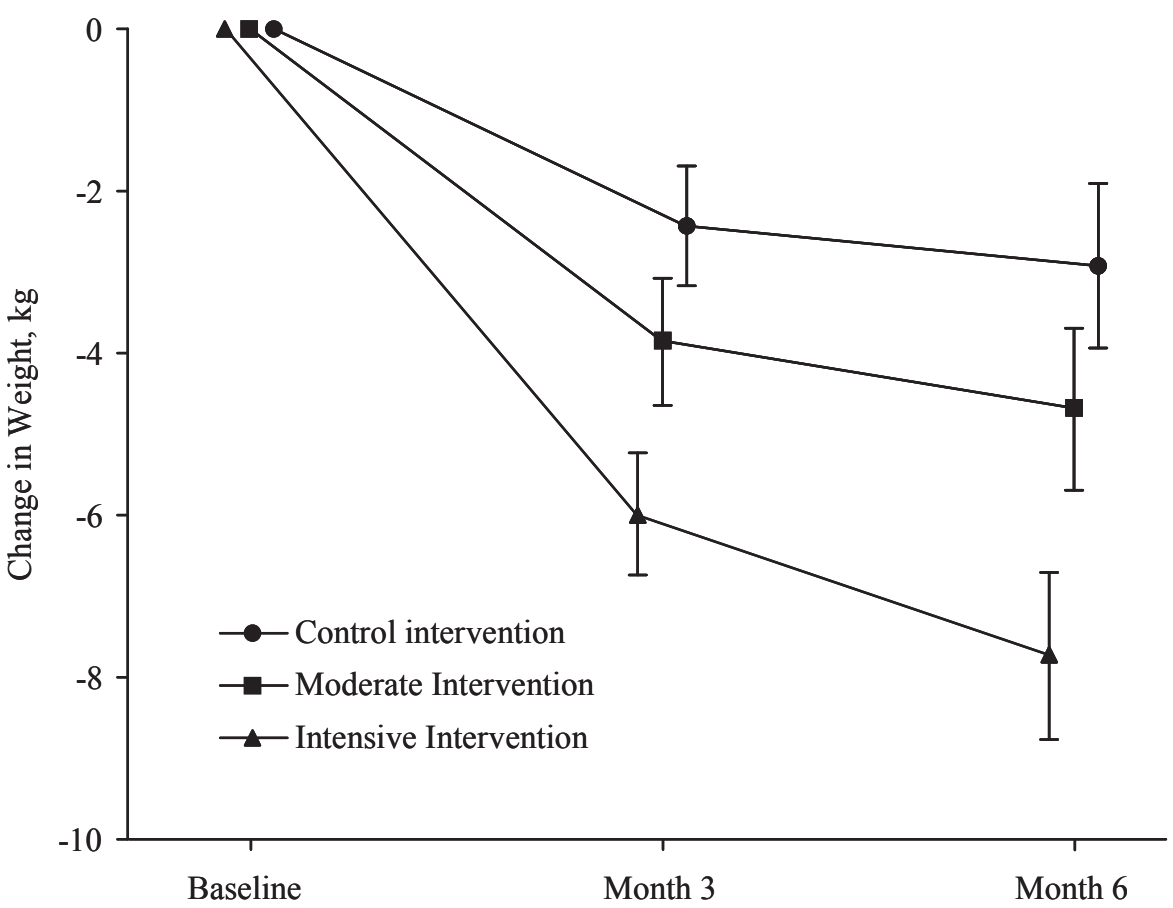

ferred alternatives to face-to-face treatment [20] as well as limited costs [3, 4]. Recent studies have reported the effectiveness of an alternative method for promoting weight loss using the internet and e-mail [21-23], text messages via mobile phones [24], or diet counselling via the telephone [25]. In this regard, education-only intervention can be a cost-effective weight loss method that requires less face-to-face contact.

Group-based intervention has a greater extent of effectiveness in achieving weight loss than the education-only intervention. A recent randomised controlled trial showed the effectiveness of high-frequent (18 times in 6 months) face-toface counselling $(8.9 \%$ loss of initial body weight) compared with self-help (5.2\%) or low-frequent (6 times in 6 months) face-to-face counselling (6.4\%) along with sibutramine use; in contrast, the effectiveness of low-frequent face-to-face counselling was not statistically significant compared with self-help [25]. In the present study, the group-based intervention was not highly frequent ( 8 times in 6 months including the instruction at week 1); however, the effectiveness (10.5\% loss of initial body weight) was clearly shown compared with the control $(4.1 \%)$ or education-only intervention $(6.4 \%)$. The results may be attributed to different approaches: group versus individual. Group treatment appears to allow participants to interact with each other and bring short-term benefits in achieving weight loss [26]. From a cost-effective perspective as well, a group-based support appears to have some advantages [27], whereas further studies are needed to demonstrate the effectiveness of a group approach compared with an individual approach.

The major strength of this study is that it was a one-phase randomised trial in which all participants started simultane- ously in a population at risk of metabolic syndrome. A low attrition rate as in the present study provides a more accurate estimate of the actual treatment effect because it reduces the potential effect of selection bias.

The present study includes some limitations. First, despite significant differences in weight loss between the three groups, the improvement in most secondary outcome measures was not statistically different. In part, this is a statistical issue because the study was powered to detect differences in the amount of weight loss, not in the secondary outcome measures. Furthermore, the secondary outcome measures of most participants were in the normal range at baseline. Therefore, not much improvement could be obtained. Second, the study length of 6 months is short because the maintenance of weight loss is necessary for enduring health benefits. We have designed a 2-year follow-up no-intervention observation period and planned to implement annual follow-up measurements for participants in the moderate and intensive intervention groups; however, due to ethical concerns, we provided the group-based support to the control intervention group after the 6-month study period. Therefore, after the 2-year follow-up, we will report the long-term residual effectiveness in achieving weight maintenance of the intensive intervention group compared with the moderate intervention group. Another limitation is that the study population included only Japanese participants who are willing and motivated, which limits the generalisation of the results. Further studies are required to confirm the generalisation to other populations.

In summary, education-only intervention can be a costeffective method for promoting weight loss that requires less face-to-face contact. This approach is potentially appropriate 
if costs in terms of time and physical effort are limited to implement intensive weight-loss intervention, or if participants prefer treatments requiring less face-to-face contact in clinical and public health settings. Group-based intervention further promotes weight loss, although it needs considerable effort from well-trained staff.

\section{Acknowledgments}

This study was supported by the Japan Agriculture Ibaraki Public Welfare Federation and partly funded by the Meiji Yasuda Life Founda- tion of Health and Welfare, 2008. We wish to thank members of Mito Kyodo General Hospital for their cooperation in data acquisition and members of the Tsukuba Critical Path Research and Education Integrated Leading Center (CREIL) at the University of Tsukuba for their critical advice in conducting the study and data management during the study period. We owe special thanks to the participants of this study and are also grateful to Yuriko Sakairi for her excellent cooperation to implement the present study.

\section{Disclosure Statement}

The authors declare no conflict of interest

\section{References}

$\checkmark 1$ Knowler WC, Barrett-Connor E, Fowler SE, Hamman RF, Lachin JM, Walker EA, Nathan DM; Diabetes Prevention Program Research Group: Reduction in the incidence of type 2 diabetes with lifestyle intervention or metformin. N Engl J Med 2002;346:393-403.

- Tuomilehto J, Lindström J, Eriksson JG, Valle TT, Hämäläinen H, Ilanne-Parikka P, KeinänenKiukaanniemi S, Laakso M, Louheranta A, Rastas M, Salminen V, Uusitupa M; Finnish Diabetes Prevention Study Group: Prevention of type 2 diabetes mellitus by changes in lifestyle among subjects with impaired glucose tolerance. N Engl J Med 2001;344:1343-1350.

3 American Diabetes Association and National Institute of Diabetes, Digestive and Kidney Diseases: The prevention or delay of type 2 diabetes. Diabetes Care 2002;25:742-749.

4 Wing RR: Behavioral interventions for obesity: recognizing our progress and future challenges. Obes Res 2003;11(suppl):3-6.

$\checkmark 5$ Dansinger ML, Tatsioni A, Wong JB, Chung M, Balk EM: Meta-analysis: the effect of dietary counseling for weight loss. Ann Intern Med 2007;147:41-50

6 Bravata DM, Smith-Spangler C, Sundaram V, Gienger AL, Lin N, Lewis R, Stave CD, Olkin I, Sirard JR: Using pedometers to increase physical activity and improve health: a systematic review. JAMA 2007;298:2296-2304.

7 Richardson CR, Newton TL, Abraham JJ, Sen A, Jimbo M, Swartz AM: A meta-analysis of pedometer-based walking interventions and weight loss. Ann Fam Med 2008;6:69-77.

8 Smith BJ, Bauman AE, Bull FC, Booth ML, Harris MF: Promoting physical activity in general practice: a controlled trial of written advice and information materials. Br J Sports Med 2000;34:262-267.

$\checkmark 9$ Heshka S, Anderson JW, Atkinson RL, Greenway FL, Hill JO, Phinney SD, Kolotkin RL, Miller-Kovach $\mathrm{K}$, Pi-Sunyer FX: Weight loss with self-help compared with a structured commercial program: a randomized trial. JAMA 2003;289:1792-1798.
10 Glasgow RE, Lichtenstein E, Marcus AC: Why don't we see more translation of health promotion research to practice? Rethinking the efficacyto-effectiveness transition. Am J Public Health 2003:93:1261-1267.

11 Nakata Y, Okada M: Effects of weight-loss tools and a group-based weight-loss support program: Rationale and study design of a randomized controlled trial (in Japanese). Nippon Koshu Eisei Zasshi 2010;57:835-842.

12 The Examination Committee of Criteria for 'Metabolic Syndrome' in Japan: Criteria for 'metabolic syndrome' in Japan (in Japanese). Nippon Naika Gakkai Zasshi 2005:94:188-203.

13 Gorin AA, Wing RR, Fava JL, Jakicic JM, Jeffery R, West DS, Brelje K, Dilillo VG; Look AHEAD Home Environment Research Group: Weight loss treatment influences untreated spouses and the home environment: evidence of a ripple effect. Int J Obes 2008:32:1678-1684.

14 Tanaka K, Okura T, Shigematsu R, Nakata Y, Lee DJ, Wee SW, Yamabuki K: Target value of intraabdominal fat area for improving coronary heart disease risk factors. Obes Res 2004;12:695-703.

15 Nakata Y, Okura T, Matsuo T, Tanaka K: Factors alleviating metabolic syndrome via diet-induced weight loss with or without exercise in overweight Japanese women. Prev Med 2009;48:351-356.

16 Kagawa A: The 'four-food-group-point-method' (in Japanese). J Kagawa Nutr Univ 1983;14:5-12.

17 Oshima Y, Kawaguchi K, Tanaka S, Ohkawara K, Hikihara Y, Ishikawa-Takata K, Tabata I: Classifying household and locomotive activities using a triaxial accelerometer. Gait Posture 2010;31:370-374.

18 Troiano RP, Berrigan D, Dodd KW, Mâsse LC, Tilert T, McDowell M: Physical activity in the United States measured by accelerometer. Med Sci Sports Exerc 2008;40:181-188.
19 Mâsse LC, Fuemmeler BF, Anderson CB, Matthews CE, Trost SG, Catellier DJ, Treuth M: Accelerometer data reduction: a comparison of four reduction algorithms on select outcome variables. Med Sci Sports Exerc 2005;37(suppl):544-554.

20 Sherwood NE, Morton N, Jeffery RW, French SA, Neumark-Sztainer D, Falkner NH: Consumer preferences in format and type of community-based weight control programs. Am J Health Promot 1998;13:12-18.

21 Tate DF, Wing RR, Winett RA: Using Internet technology to deliver a behavioral weight loss program. JAMA 2001;285:1172-1177.

22 Tate DF, Jackvony EH, Wing RR: Effects of Internet behavioral counseling on weight loss in adults at risk for type 2 diabetes: a randomized trial. JAMA 2003;289:1833-1836.

23 Tate DF, Jackvony EH, Wing RR: A randomized trial comparing human e-mail counseling, computer-automated tailored counseling, and no counseling in an Internet weight loss program. Arch Intern Med 2006;166:1620-1625.

24 Patrick K, Raab F, Adams MA, Dillon L, Zabinski M, Rock CL, Griswold WG, Norman GJ: A text message-based intervention for weight loss: randomized controlled trial. J Med Internet Res 2009;11:e1.

25 Digenio AG, Mancuso JP, Gerber RA, Dvorak $\mathrm{RV}$ : Comparison of methods for delivering a lifestyle modification program for obese patients: a randomized trial. Ann Intern Med 2009;150:255262.

26 Befort CA, Donnelly JE, Sullivan DK, Ellerbeck EF, Perri MG: Group versus individual phonebased obesity treatment for rural women. Eat Behav 2010;11:11-17.

27 Renjilian DA, Perri MG, Nezu AM, McKelvey WF, Shermer RL, Anton SD: Individual versus group therapy for obesity: effects of matching participants to their treatment preferences. J Consult Clin Psychol 2001;69:717-721. 